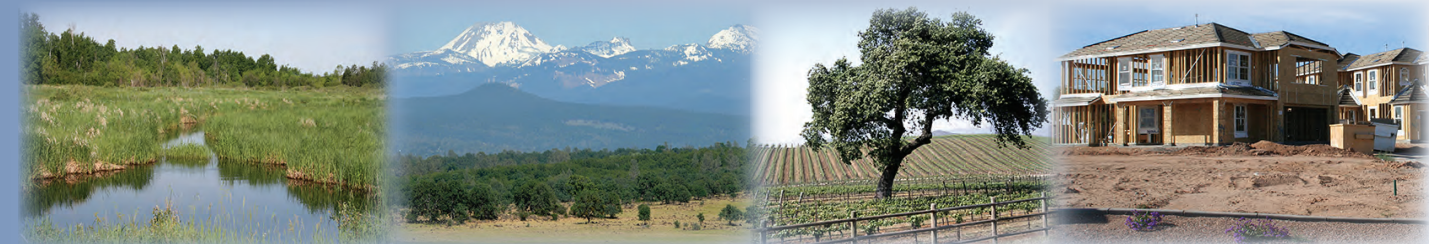

\title{
Land Change Monitoring, Assessment, and Projection
}

There is a pressing need to monitor and understand the rapid land change happening around the world. The U.S. Geological Survey is developing a new capability, called Land Change Monitoring, Assessment, and Projection (LCMAP), to innovate the understanding of land change. This capability is the Earth Resources Observation and Science Center's foundation for an integrated U.S. Geological Survey-wide land change science framework. LCMAP supports the development of consistent data and land cover products spanning large geographic extents, over extended periods, and at a higher frequency than in the past (fig. 1; Brown and others, 2020). LCMAP provides solutions to the science and management communities' growing need for an improved understanding of the fundamental drivers of land change, the consequences of change in human and natural systems, and feedbacks associated with land change processes.

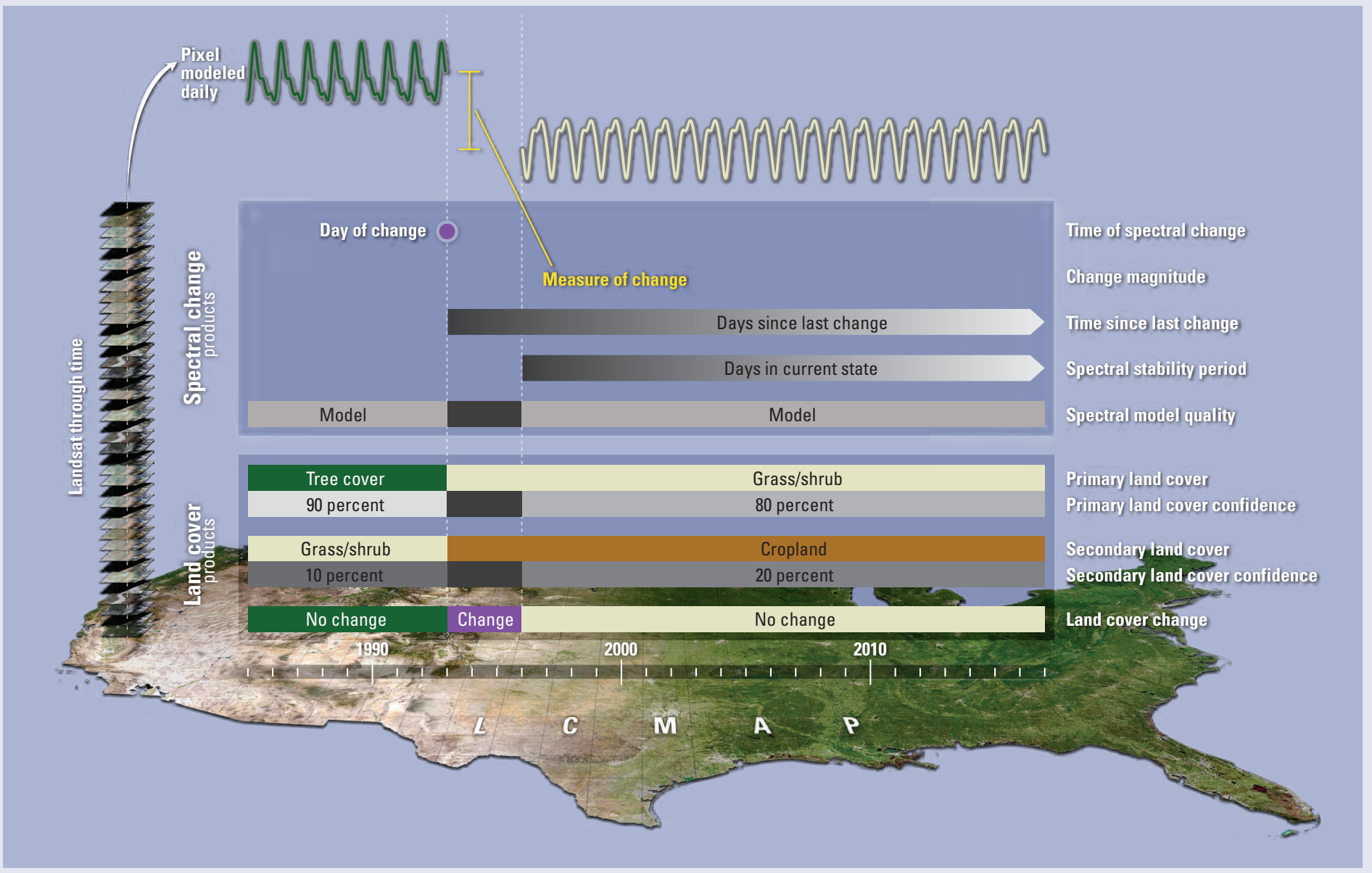

Figure 1. LCMAP produces land cover change information for every location in the United States for the Landsat 4 through Landsat 8 record. Landsat Analysis Ready Data, coupled with the Continuous Change Detection and Classification algorithm, provide models for every location based on the spectral and temporal properties of the land surface. The 5 spectral change products and 5 land cover products are based on model results.

\section{LCMAP provides unprecedented new land change information, including the following:}

- Analytical capabilities to monitor land cover and land cover change and evaluate vegetation condition.

- Data describing past, present, and future landscapes.

- Support for a range of applications relevant to environmental management and policy.
- Assessments of the rates, causes, and consequences of land change.

- Sharing of all data, information, and knowledge with the community.

- Access to data, visualization, and tools.

- Continuous tracking of land change. 


\section{Monitoring}

Monitoring a changing land surface through time with high frequency is now feasible. With current technology, the Landsat satellite archive is used for the characterization of land dynamics across large spatial areas. Although past large-scale efforts have tended to map only a few reference dates, LCMAP allows far more reference dates because the basic unit of analysis for LCMAP is the time series of satellite measurements at a pixel location (a 30-meter [m] by 30-m square). Each pixel time series is analyzed for change, allowing change to be dated more precisely than in past efforts (fig. 2). The time-series approach can produce consistent results across variable observation frequencies and improve the robustness of the modeling approach. LCMAP provides annual products that are updated regularly. Semiannual, and even more frequent, updates are a topic of continuing research.
The analysis approach for LCMAP is based on the Continuous Change Detection and Classification algorithm. Landsat Analysis Ready Data are the main input for LCMAP (Dwyer and others, 2018). Spectral change detection is run for each pixel time series, and model information from each pixel is used as input for land cover classification. The time-series approach means that LCMAP results are continuously applicable across the period of record (mid-1980s to present), whereas initial LCMAP land cover products are annual snapshots. Other sources of data, such as Sentinel-2, are targeted for future incorporation to increase observation frequency.

LCMAP accuracy is checked using an independent reference dataset collected by interpreters using satellite and other data. The reference data include land cover for each year from 1984 to present (2017) at 25,000 randomly selected sample sites across the United States. The national accuracy assessment report for LCMAP monitoring products is produced from these data.
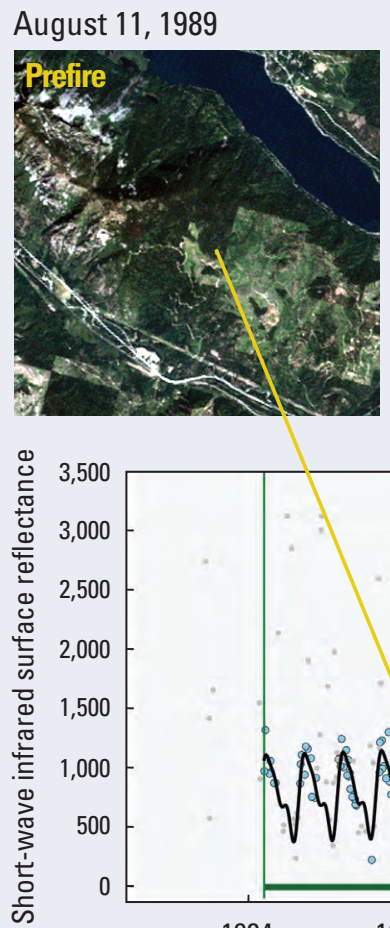

August 16, 1994

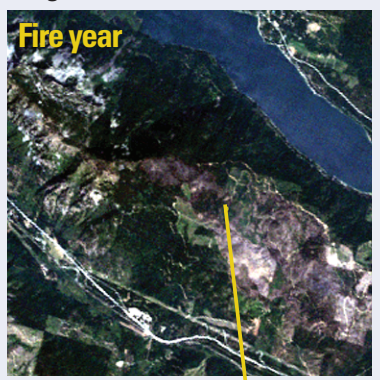

October 14, 2004

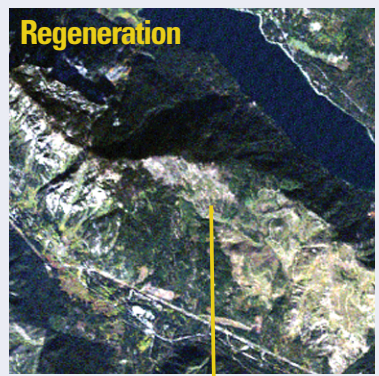

July 11, 2016

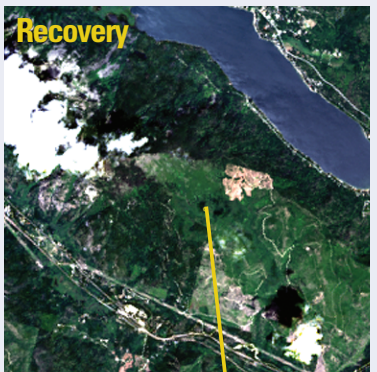

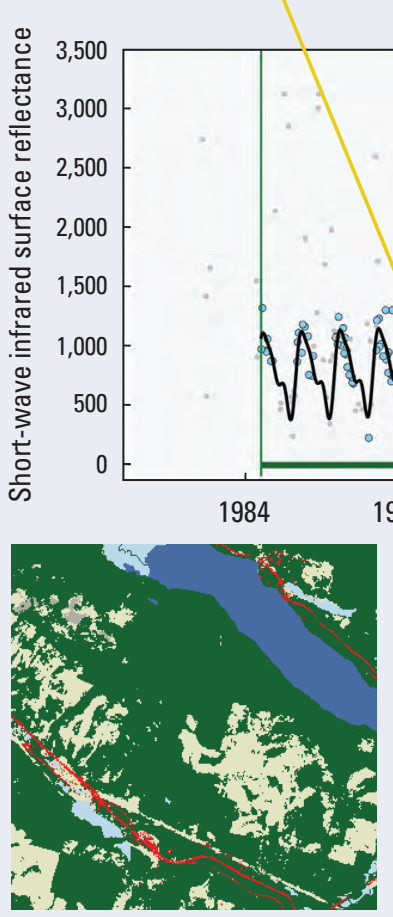

1989

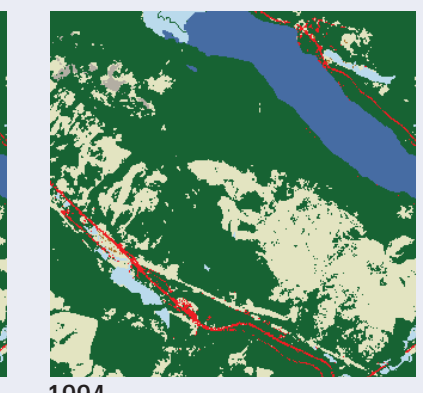

1994

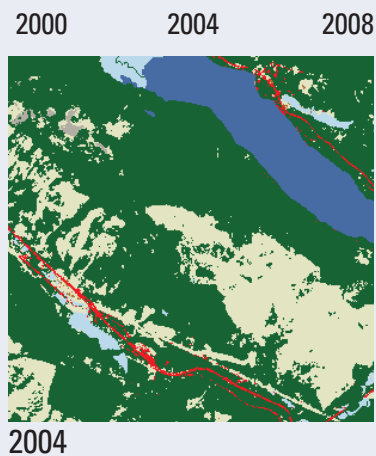

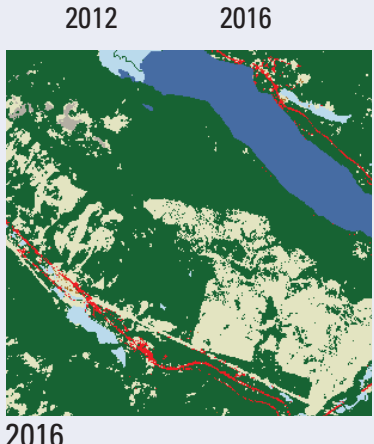

2016
EXPLANATION

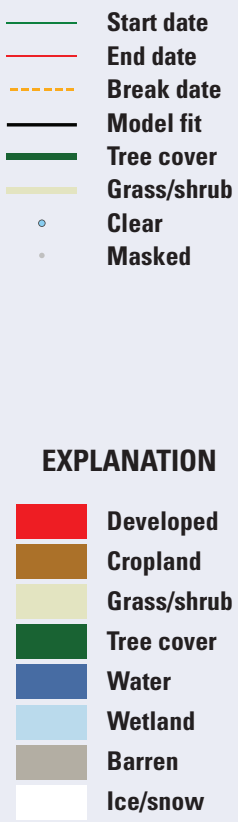

Ice/snow

Figure 2. Model results of Continuous Change Detection and Classification algorithm for a forested pixel showing the effects of wildfire in the State of Washington. The Round Mountain fire occurred in late summer, 1994. The annual Primary Land Cover product shows regeneration as a grass/shrub land cover after the fire. By 2016, the land cover indicates that parts of the fire area recovered, characterized by mature trees, and classified as tree cover. 


\section{Assessment}

High temporal frequency land change mapping offers a new opportunity to better understand U.S. land use and land cover (LULC) change processes. Improving our understanding of these land dynamics allows further research into a myriad of environmental change issues and advances their geographic and temporal scope. Initial LCMAP regional-to-national scale assessments address the fundamental questions regarding change: where did change occur, how much change occurred, what were the rates of change, and what caused the change? LCMAP assessments can use these data to compile change statistics to better understand the dynamics of national and regional land use through time (fig. 3). This new knowledge can then be used in scientific investigations, applications, and land management to address a variety of issues.

\section{Projection}

LULC projections created from LCMAP can be integrated seamlessly, enabling analyses of past, current, and future landscape effects on biodiversity, hydrology, climate and weather, and other relevant processes. LULC modeling components include (1) "projecting" or temporally extending land cover into future and historical time periods (when remote sensing data are not available) and (2) facilitating the application of modeled landscape data. A LULC model called Forecasting Scenarios (FORE-SCE) produces 30-m spatial resolution landscape projections that match the spatial, temporal, and thematic characteristics of LCMAP land cover. FORE-SCE employs actual land management parcels for spatial modeling to ensure a realistic and detailed representation of landscape pattern (fig. 4).
Figure 3. Annual land cover class change condensed into multiyear intervals shows phases of development around the city of Charlotte, North Carolina. The center of Charlotte shows no change (black), whereas areas of change since 1986 are shown in color. Interstate 485, known as the Outerbelt, forms a circle around the city. Urban expansion near Interstate 485 is evident. A reservoir constructed in the early 1990s can be seen north of Charlotte. The lower right corner of the image has concentrated patches of land cover class change. Many of these changes are related to the cyclic harvest and regrowth of timber for commercial forest harvest.

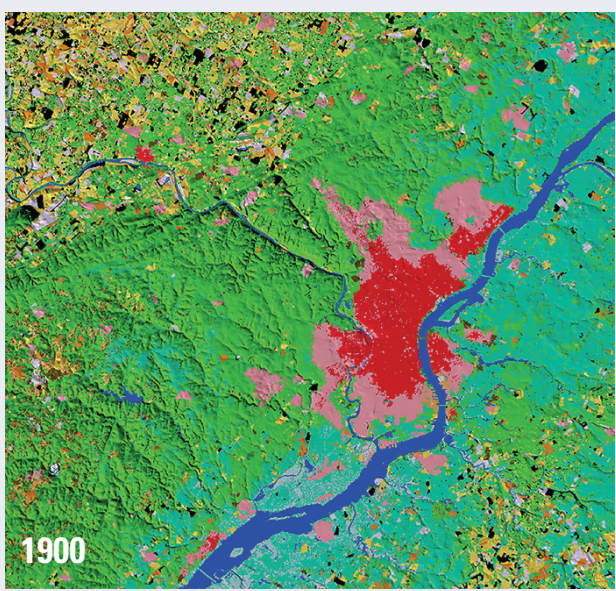

Figure 4. Modeled historical, current, and projected land cover for the Philadelphia, Pennsylvania, area. The FORE-SCE model can be used to model historical landscape change and scenarios of future conditions, resulting in a consistent, long-term land cover database.
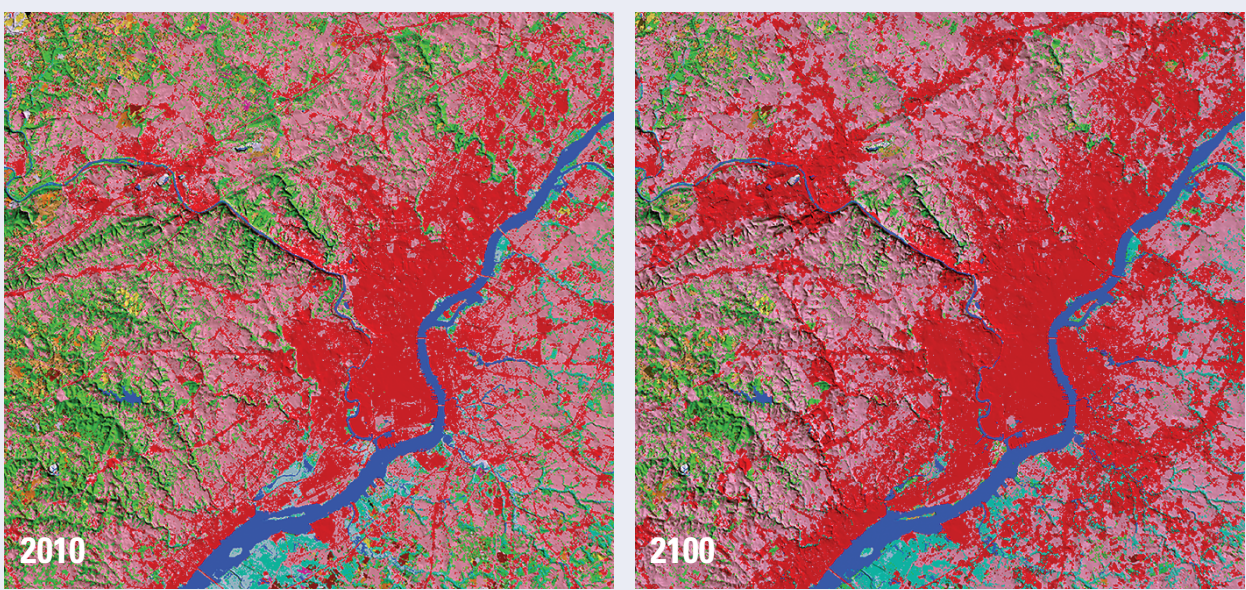

EXPLANATION

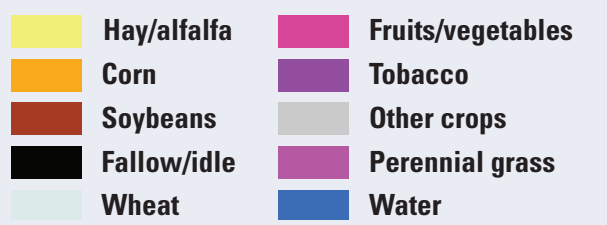

Low-density urban

High-density urban Barren

Deciduous forest Evergreen forest
Mixed forest

Shrubland Grassland Woody wetland Herbaceous wetland 


\section{LCMAP Land Change Story Example- Tornadoes of the 2011 Super Outbreak}

On April 27, 2011, a record number of tornadoes touched down across the southern United States, causing loss of life and property. Landsat observations confirmed the tornadoes' destructive paths. The Tuscaloosa and Birmingham, Alabama, area is shown in figure 5 several weeks before the April tornadoes. In figure 6, multiple tornado paths are visible across the land surface in June, after the late April tornado outbreak.

LCMAP produces several products that greatly enhance our understanding of this event. The Annual Land Cover Change product (fig. 7) indicates the land cover class of the land surface and where a change occurred each year. The LCMAP spectral change products include maps of when a change occurred by estimating a day of year (fig. 8) and the magnitude of spectral change, as indicated by Landsat data (fig. 9).

\section{References Cited}

Brown, J.F., Tollerud, H.J., Barber, C.P., Zhou, Q., Dwyer, J.L., Vogelmann, J.E., Loveland, T.R., Woodcock, C.E., Stehman, S.V., Zhu, Z., Pengra, B.W., Smith, K., Horton, J.A., Xian, G., Auch, R.F., Sohl, T.L., Sayler, K.L., Gallant, A.L., Zelenak, D., Reker, R.R., and Rover, J., 2020, Lessons learned implementing an operational continuous United States national land change monitoring capability-The Land Change Monitoring, Assessment, and Projection (LCMAP) approach: Remote Sensing of Environment, v. 238, art. 111356. [Also available at https://doi.org/10.1016/j.rse.2019.111356.]

Dwyer, J.L., Roy, D.P., Sauer, B., Jenkerson, C.B., Zhang, H.K., and Lymburner, L., 2018, Analysis Ready Data-Enabling analysis of the Landsat archive: Remote Sensing, v. 10, no. 9, art. 1363, 73 p. [Also available at https://doi.org/10.3390/ rs10091363.]

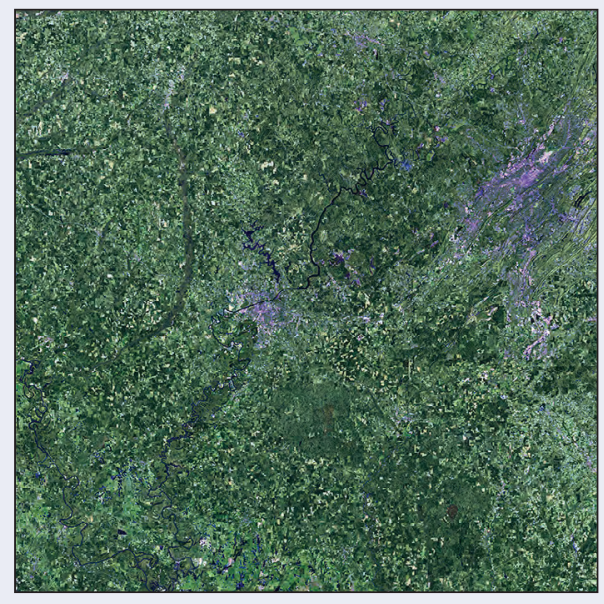

Figure 5. Landsat data showing the Tuscaloosa and Birmingham, Alabama, area several weeks before the late April 2011 tornado outbreak.

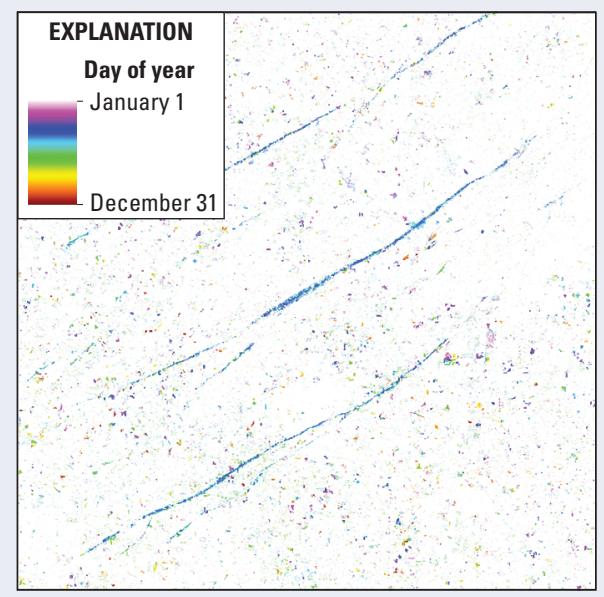

Figure 8. LCMAP Time of Spectral Change product estimates the day of year when a change occurred. The estimate of timing for areas affected by the tornadoes was early May 2011, just after the deadly storm.

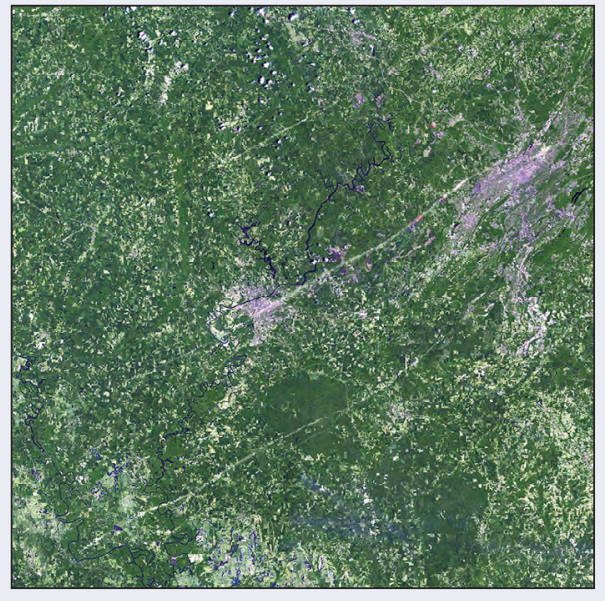

Figure 6. Landsat data showing tornado paths in the Tuscaloosa and Birmingham, Alabama, area in June 2011, after the late April 2011 tornado outbreak.

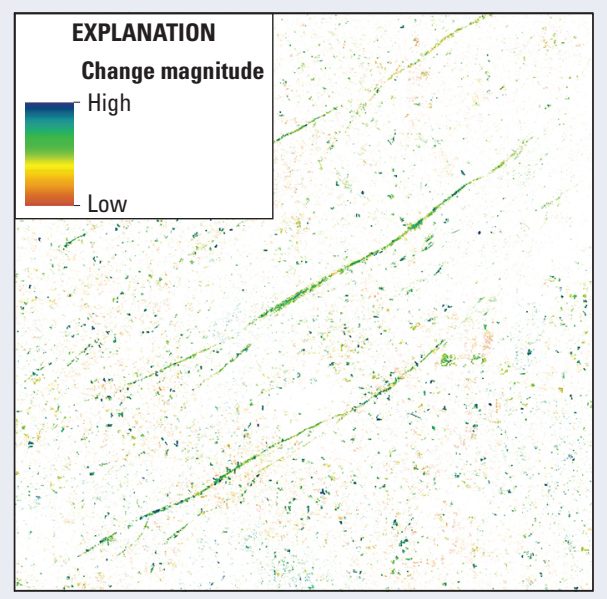

Figure 9. Three distinct tornado paths are visible in the LCMAP Change Magnitude product. Other land changes also are captured as patches. The surface changes caused by the tornadoes were moderate for this location.

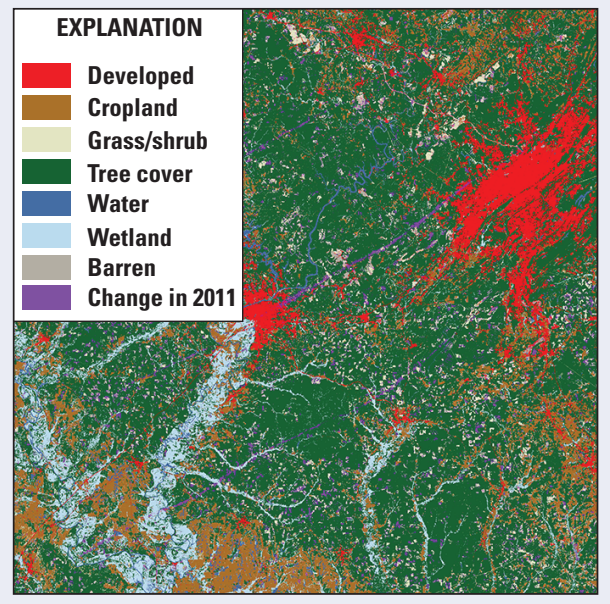

Figure 7. LCMAP Annual Land Cover Change product showing the Tuscaloosa and Birmingham, Alabama, area on July 1, 2011, after the tornado outbreak. Land surfaces affected by the tornadoes were mapped as a change in the LCMAP Land Cover Change product.

For additional information about Land Change Monitoring, Assessment, and Projection, please visit:

https://www.usgs.gov/land-resources/eros/lcmap

For more specific questions about the LCMAP initiative, contact

U.S. Geological Survey, Customer Service

Earth Resources Observation and Science Center

Sioux Falls, SD 57198

Phone: 605-594-6151 or 1-800-252-4547

Email: custserv@usgs.gov

Twitter: \#LCMAP

Publishing support provided by the Rolla Publishing Service Center

ISSN 2327-6916 (print) ISSN 2327-6932 (online) https://doi.org/10.3133/fs20203024 